\title{
Combined Learning Models Based on Constructionism Applied in Modern Learning of Biology
}

Iancu M. Mariana, Bioterra University of Bucharest, Bucharest, Romania

\begin{abstract}
The purpose of this research has been to identify modern and effective learning models, based on constructionism, in learning biological concepts. The author shows that the cognitive, formative, and emotional benefits, of combined learning models to obtain the best results in the construction of concepts, by students' effort, in accordance with Papert's constructionism ideas. The researcher recommends using the technoempirio-psycho-sociocentric (TEPS) combined model, based on information and communication technologies (ICTs), in individual-and team-based rediscovery of new biological concepts. When no ICTs are used, the empirio-psycho-socio-centric model is recommended. As an alternative or in combination with, these learning models, the researcher promotes the techno-logo-psychocentric (TLP) model in presentations of science as a finished product when ICTs are used or the logo-psychocentric modernized (LPM) model, with attractive procedures, without ICTs.
\end{abstract}

\section{KEYWORDS}

Empirio-Psycho-Sociocentric (EPS) Model, Information and Communication Technologies (ICTs), Learning by Rediscovery, Logo-Psychocentric Modernized (LPM) Model, Seymour Aubrey Papert, Techno-Empirio-Psycho-Sociocentric (TEPS) Model, Techno-LogoPsychocentric (TLP) Model 


\section{INTRODUCTION}

Globalization and technological change have been transforming university and preuniversity education, connecting it to modern learning models based on constructionism by applying it mainly to new technologies and to learning through rediscovery, which contribute to the training of young people's professional skills and their training for life. According to Daniela and Lytras (2018), "Every individual in the globalised world more and more frequently faces the challenge to change or [to] improve the previously acquired competences. For the economy to progress, the education sector has to be the first that is able itself to adjust flexibly and to apply innovations for the development of the individuals' knowledge, skills and competencies." (p.1).

Constructionist learning is when learners construct mental models to understand the world around them and to discover it, when people are active in making tangible objects in the real world, and builds on Jean Piaget's epistemological theory of constructivism. While Piagetian Constructivism sees children as active builders of knowledge (Papert, 1999), Papert's Constructionism expands it by attaching particular importance to the role of concrete buildings in the world-as a support for his conception of mental constructs - in the form of a 'product' of a more public sort, which can be shown, discussed, examined, probed, and admired ... be that product a sand castle, a computer program, a poem, or a theory of the universe (Papert, 1993, p. 142).

As shown by Alesandrini and Larson (2002), constructionism advocates studentcentered discovery learning where students use information they already know to acquire more knowledge, "Rather than requiring an understanding before applying that understanding to the construction of something, students in a constructivist classroom learn concepts while exploring their application. During this application process, students explore various solutions and learn through discovery" (p. 118). Given the changes occurring in education in the Knowledge Society of the 21 st century, here are some questions that have guided the author in her research in correlation with constructionism:

- "Can the traditional training model really meet the new requirements for the training of students in contemporary society?"

- "Given the growing need to improve lives and the environment, would it be necessary to promote a biology-focused education that would foster a spirit of inquiry, intellectual activity, active thinking, and fast and accurate judgment, to put students in the position of searching for solutions and cooperating in investigations?"

- "What would be the didactical models that would best contribute to the formation of such personalities?"

The researcher tried to find answers not only to these questions, but also to other questions that came along, in order to learn about biology (bios = life; logos = science, speech), which is the branch of science that "studies the morpho-physiological 
characteristics, the origin, the evolution, the reproduction, the heredity, and so on of living organisms" (Petruţa, 2009, p. 13).

The Organisation for Economic Co-operation and Development (OECD) showed in 2015 that "Advances in information and communication technologies (ICTs) are bringing about new opportunities and [are] having an impact on teaching and learning methods, mainly through what is commonly known as "e-learning" (p.13).

In this sense, the researcher considered the promotion of the use of informational and communicational technologies (ICTs) in combination with the rediscovery (depending on the students' individual particularities and on the students' age particularities) and the promotion of individual rediscovery or rediscovery in team, this combination corresponding to the techno-empirio-psycho-sociocentric (TEPS) combined model. Also, the researcher considered the promotion of the techno-empiriopsycho-sociocentric (TEPS) combined model, when the curriculum, the material base of the biology laboratory, or the ICT competences of the students allow for the use of the elements corresponding to the technocentric (T) model in combination with elements of the empiriocentric $(\mathrm{E})$, psychocentric $(\mathrm{P})$, and sociocentric $(\mathrm{S})$ models. The techno-empirio-psycho-sociocentric (TEPS) combined model is based on Papert's constructionism, which showed that "The simplest definition of constructionism evokes the idea of learning-by-making" (Papert \& Harel, 1991, par. 14).

When no informational and communicational technologies are used, an empiriopsycho-sociocentric (EPS) combined model. Also, the researcher considered the promotion in alternation with, or even in combination with, the techno-empirio-psychosociocentric (TEPS) combined model and the empirio-psycho-sociocentric (EPS) combined model based on rediscovery strategies, the logo-psychocentric modernized (LPM) model, of presenting science as a finite product, with respect to the students' individual particularities, based on attractive procedures. Also, one model considered by the researcher is the techno-logo-psychocentric (TLP), which is combined with elements of the technocentric (T) model.

The purpose of the research is to identify modern and effective learning models based on constructionism principles in learning biological concepts-their cognitive, formative and affective benefits; the limits and conditions of the application of some didactical models in the learning of biology.

The objectives that result from this purpose are both general and particular in nature. Among the most important general objectives that result from the purpose of the research presented in the article are:

- The identification of situations for the learning of biological concepts through the of combined learning models based on constructionism and rediscovery in according to scientific content, courses, lessons, information sequences from lessons, notions that are suitable for rediscovery and constructionism, conditions that would encourage the combined learning models, the cognitive and operational structures, intellectual capacities, methods and techniques that can be used in their success; 
- The identification of learning situations that are likely to provoke cognitive and socio-cognitive conflicts; and

- The identification of biological concepts that allow for the application of the modernized techno-logo-psychocentric (TLP) learning model using a laptop, the Internet, and videoclips; computer-programmed training sheets, and working sheets; and the inter- and trans-correlations of biology with other disciplines such as literature, art, informatics, and the English language which, to be attractive, requires demonstrative material designed in a way that stimulates students' thinking; etc.

Among the most important particular objectives that result from purpose of the research presented in the article are:

- Assimilating by students of fundamental biological principles such as "structurefunction" correlation, "body-environment" correlation, and "unity-diversity";

- Tracking how students train their psychomotor skills; and

- Training / developing work skills.

\section{THE COMBINED LEARNING MODELS, BASED ON CONSTRUCTIONISM IN THE LEARNING OF BIOLOGY: BACKGROUND}

The learning model in didactic of biology is a system that, through various values or qualities, can serve as an example for the learning of biological concepts by pupils and students, in the educational processes in secondary schools and universities.

In addition to the dominant pedagogical perspective, there are several main learning models in the didactic process, namely:

- The technocentric (T) model;

- The empiriocentric (E) model;

- The psychocentric (P) model;

- The sociocentric (S) model;

- The logocentric (L) model; and

- $\quad$ The combined (mixed) models (EPS, LPM, TEPS, TLP).

The combined learning model is a learning model which combines certain values of several models - which, through compensation and complementarity, can contribute to eliminating some short comings and disadvantages of the learning models' components (applied separately).

Such combined learning models used in the learning of the biological disciplines are the empirio-psycho-sociocentric (EPS) model, the techno-empirio-psychosociocentric (TEPS) model, the techno-logo-psychocentric (TLP) model, and the logo-psychocentric modernized (LPM) model, which are based on constructionism. 
According to Ackermann, Gauntlett, \& Weckstrom (2009), “constructionism is a constructivist learning theory and [a] theory of instruction. It states that building knowledge occurs best through building things that are tangible and sharable" (p. 56).

Stager Gary (2005) showed eight big ideas behind the constructionist learning lab by Seymour Aubrey Papert, a contemporary American scientist and educator, one of the pioneers of artificial intelligence, and of the constructionist movement in education. These ideas are:

1. Learning by doing;

2. Technology as building material (which is especially true for digital technology);

3. Learning to learn;

4. Hard fun (learning and working best if they enjoy what they are doing);

5. Not being able to get something right without getting it wrong, because nothing important works for the first time; the only way to get it right is through feedback; looking carefully at what happened when something went wrong; doing, and by one self, the same tasks that we give to our students; every difficulty we run into is an opportunity to learn; the best lesson educators can give our students is to let them see us struggle to learn;

6. Taking time, and doing everything that is important; you have to learn to manage time for yourself;

7. Knowing about digital technology is as important as reading and writing; learning about computers is essential for students' futures, but the most important purpose is using them now to learn about everything else, including biology.

The researcher presents in this paper the combined learning models identified: the empirio-psycho-sociocentric (EPS) model, the techno-empirio-psycho-sociocentric (TEPS) model, the logo-psychocentric modernized (LPM) model, and the technologo-psychocentric(TLP) model, as follows.

\section{The Empirio-Psycho-Sociocentric (EPS), Heuristic- Psycho-Sociocentric (HPS), Model (Figure 1)}

As announced by researcher Ciobanu (2003), a modern perception of the learning model, centered on intellectual and psychomotor efforts of pupils and students, refers to the application of combinatorial elements of different didactic models such as rediscovery (the core of the empiriocentric (E) model), individual activity (the nucleus of the psychocentric (P) model), and interactive activity (the core of the sociocentric (S) model). All in a balanced combination in order to obtain cognitive, formative, and affective benefits, in order to eliminate or to reduce disadvantages, limitations, and conditions with regard tothe application of each model-empiriocentric (E), psychocentric (P), and sociocentric (S) models-to the education of pupils/students from schools/universities. As Alesandrini and Larson (2002) showed, constructionism is a student-centered method, a discovery learning process where students take the information they have already assimilated and use it to acquire more knowledge. 


\section{The Techno-Empirio-Psycho-Sociocentric(TEPS) Model}

In a Knowledge Society, is necessary to apply elements of the technocentric (T) model, as shown by Iancu (2018a), "The beginning of the third millennium is marked by a society dominated by knowledge, by the development of Smart Technologies which has triggered ... substantial changes in education, both in teaching and learning and which contribute to Smart Sustainable Education and to sustainable environment and society" (p. 69198), in the meaning of their creating and a more close-knit society. But in biology, it is necessary to apply elements of the technocentric (T) model in combination with elements of other models-e.g. the empiriocentric (E), psychocentric (P), and sociocentric (S) models-namely, the techno-empirio-psychosociocentric (TEPS) combined model for the realization of didactical objectives from the curriculum.

The techno-empirio-psycho-sociocentric (TEPS), techno-heuristic-psychosociocentric (THPS), model (Figure 2) is a modern learning model which is centered on practice of technique and on the intellectual and psychomotor efforts of pupils and students in rediscovery - both individually and as a team.

This combined model refers to the application of combinatorial elements of different didactic models such as the training assisted by new information and communication technologies and e-learning (the core of the technocentric (T) model), rediscovery (the core of the empiriocentric (E) model), individual activity (the nucleus of the psychocentric (P) model), and interactive activity in a team (the core of the sociocentric (S) model) - all in a balanced combination.

The application of this model in pre-university and university education advantages cognitive, formative, and affective benefits. Is its being based on elements of constructionism such as technology being building materials (which is especially true for digital technology). Other such elements include learning by doing and learning to learn. Knowing about digital technology is as important as reading and writing; and that learning about computers is essential for our students' futures. Its most important purpose is using them now to learn about everything else, including biology.

The model can be considered as being a complex of didactic engineering operations driven by the development of the computer and of Informational and Communication Technologies and animated by individual rediscovery and in a team. However, the condition of its application represented competences of the teacher/professor necessary for the technology-enhanced learning process. "It is necessary to introduce changes in teacher education in order to include the acquisition of competences necessary for the technology-enhanced learning process [,] both organizing the learning process and developing new and innovative didactic means that promote learning as well as using digital technologies" (Daniela, Kalniņa, \& Strods, 2017, p. 79).

\section{The Logo-Psychocentric Modernized (LPM) Model}

As shown by Cerghit (2008), "The revolution of knowledge has been shaped with even more vigor than another philosophy or conception about science, which necessarily leads to the philosophy of another type of education, one reconsidered in another spirit 
Figure 1. The scheme of the empirio-psycho-sociocentric (EPS) combined learning model

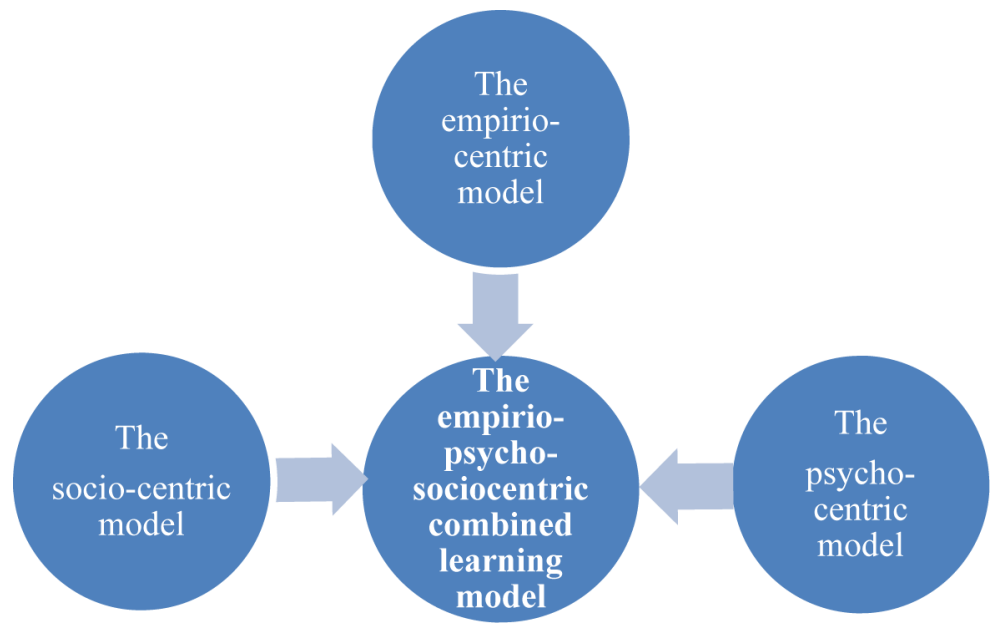

Figure 2. The scheme of techno-empirio-psycho-sociocentric (TEPS) combined learning model

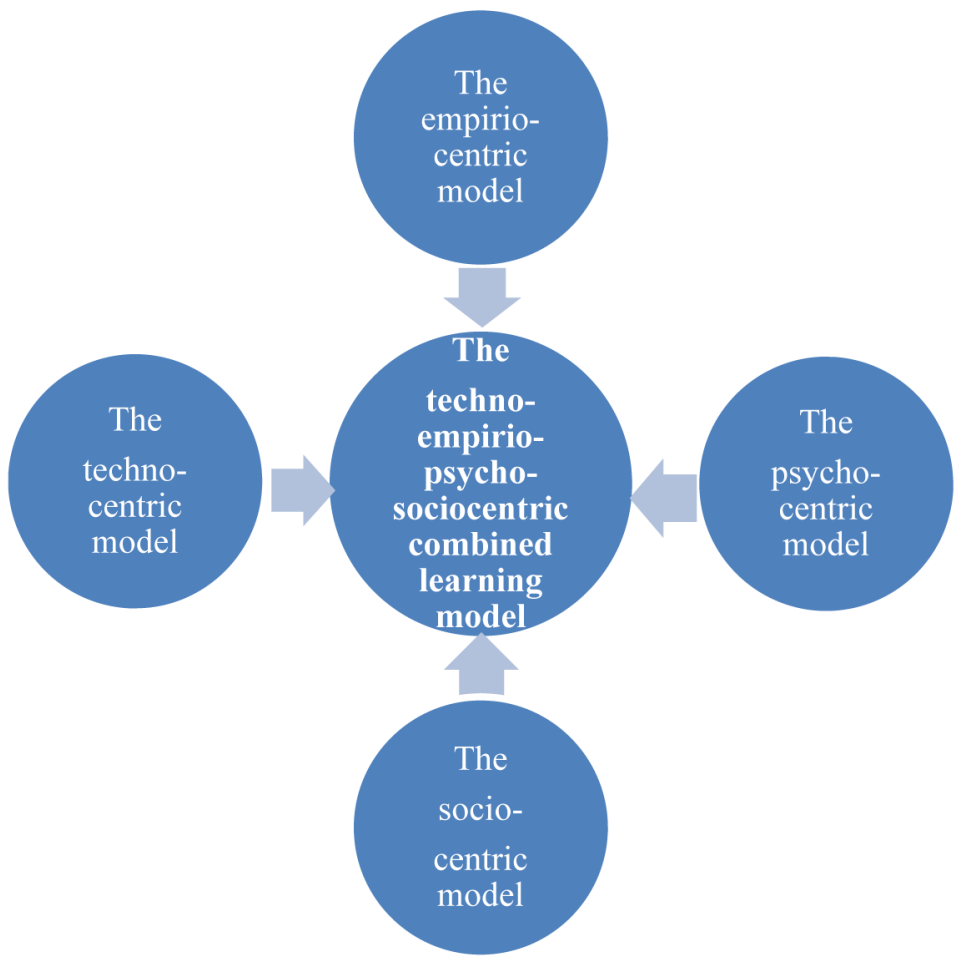


in which youth must be formed ... in this vision, scientific knowledge is perceived as being both an idea and an action, at the same time" (p.13). In accordance with this vision, the logo-psychocentric (LP) model, with attractive procedures (Figure 3 ) enounced by researcher Ciobanu (2003), is a modernized traditional model that use practices inspired from learning by the traditional logocentric (L) model, presenting science as a finished product; but, in correlation with the elements of the psychocentric (P) model, adapted to the individual and age-related particularities of students, and to the centralization of didactic activity on the use of the most attractive and productive procedures_contributing to higher cognitive improvements.

\section{The Techno-Logo-Psychocentric(TLP) Model}

According to Daniela and Lytras (2018), “There is substantial evidence proving that technological solutions fascinate learners [;] that virtual reality provides the ability to take a look in the past and in the future [; and] that it is possible to promote the development of an inclusive society and [to] lessen the risks of social exclusion by implementing learning technologies in the learning process" (p.2). The researcher showed that in the learning of biology, in accordance with the curriculum, schools and universities have a technique-material basis, but with pupils'/students' particularities, one learning model can be applied which combines elements of the technocentric (T) model with elements of the logocentric (L) and psychocentric (P) models; this combination corresponds to the techno-logo-psychocentric (TLP) combined model.

The techno-logo-psychocentric (TLP) model with attractive procedures (Figure 4) is a modernized traditional model that uses practices inspired from learning the traditional logocentric (L) model, presenting science as a finished product. In correlation with the elements of the technocentric (T) model, such as the use of the computer (informatics programs). With the elements of the psychocentric (P) model adapted to the individual and age-related particularities of pupils/students, and to use

Figure 3. The scheme of logo-psychocentric with the attractive procedures combined learning model

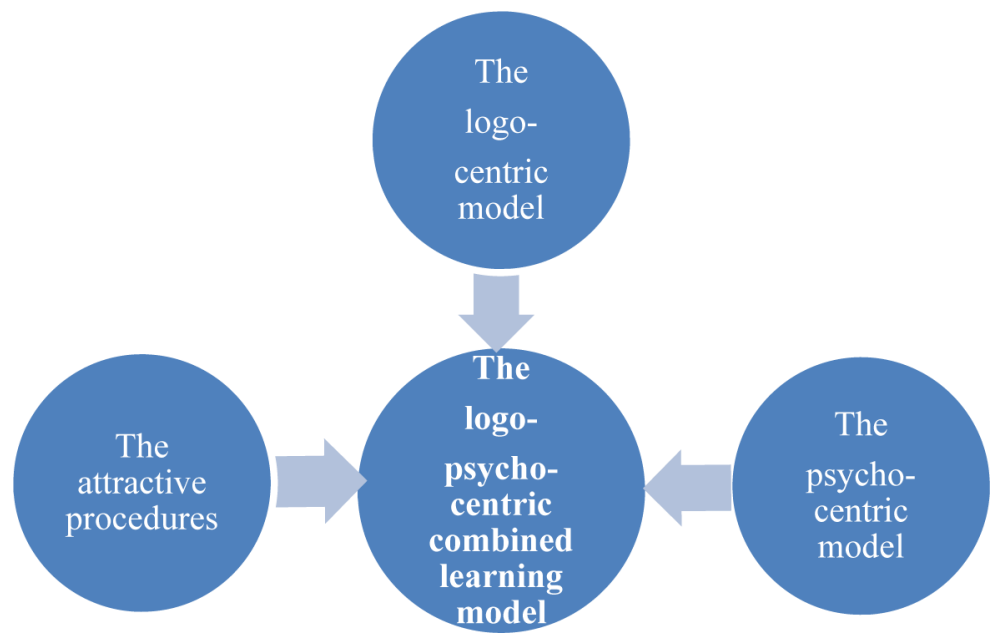


of the most attractive and productive procedures (e.g. computer-programmed training sheets and working sheets; and the inter- and trans-correlations of biology with others disciplines such as literature, music, art, informatics, and the English language) contributing to higher cognitive improvements.

The constructionism of biological concepts by combined models, the technoempirio-psycho-sociocentric (TEPS) model by rediscovery with the ICTs, the empirio-psycho-sociocentric (EPS) model by rediscovery without ICTs, the technologo-psychocentric (TLP) model by the presentation of science as finished product with ICTs, and the logo-psychocentric with attractive procedures (modernized) (LPM) model by the presentation of science as finished product without ICTs, but with attractive procedures, centered on the work and efforts of pupils and students. These combined models correspond to Papert's (1987) of constructionism. Papert defined constructionism in a proposal to the National Science Foundation entitled "Constructionism: A New Opportunity for Elementary Science Education" as follows: "The word constructionism is a mnemonic for two aspects of the theory of science education underlying this project. From constructivist theories of psychology we take a view of learning as a reconstruction rather than as a transmission of knowledge. Then we extend the idea of manipulative materials to the idea that learning is most effective when [it is] part of an activity [that] the learner experiences as constructing a meaningful product" (par. 1).

Figure 4. The scheme of techno-logo-psychocentric (TLP) combined learning model

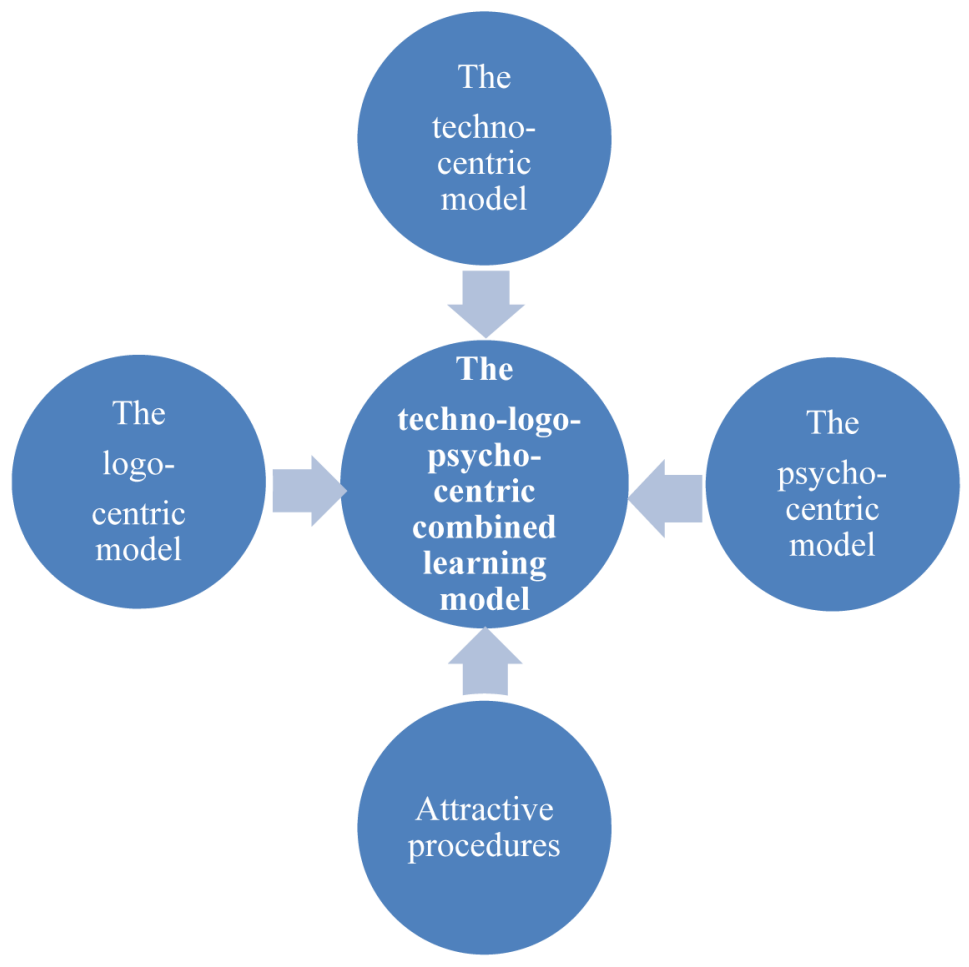


The author of this paper has shown that in biology, much of biological educative requirements under the of the curricula-i.e., the concepts related to the study of cytology, microbiology, histology, the anatomy and physiology of plant and animals, the anatomy and physiology of the human body, and so on-have been best realized to students in terms of its of refresh by offering ways to stimulate students' cognitive activism in the constructionism of concepts. Therefore, emphasis should be on productive activism-on creativity, and on the use of procedures which students find attractive (procedures which can also be used for their training for life), that assure effectiveness of the instruction being correlated with a reduction in the use of traditional logo-based method.

\section{THE EMPIRIO-PSYCHO-SOCIOCENTRIC(EPS) COMBINED LEARNING MODEL-COGNITIVE, FORMATIVE AND EMOTIONAL BENEFITS}

As shown by Iancu (2018b), the empirio-psycho-sociocentric (EPS) combined didactical model and the rediscovering of strategies in constructionism of biological concepts both contribute to realizing a competitive biological education, one which is both accessible and attractive, which can be used to train ...students for life, for a better education for them. In this way, it creates the possibility of obtaining certain advantages relative to cognitive level, in a formative and an emotional capacity, where formative means psychomotor capacity.

At the cognitive level:

- The development of new cognitive structures through the use of individual and team activities;

- The improvement of knowledge and understanding of targeted biological concepts;

- The durability and retention of learned knowledge; and

- The functionalability to operationally use that knowledge.

The results obtained from tests following the application of the corresponding empirio-psychosociocentric (EP) combined model are better than in the traditional (reproductive) model, when a teacher/professor presents the science as a finished product. This was demonstrated by the results obtained all $9^{\text {th }}$ classes - as at the "Ion Luca Caragiale" National Collegium in Bucharest in 2014 (Figure 5).

I.A.: Overall average of the initial assessment sample $\left(8.05-9^{\text {th }}\right.$ class $A, 8.20-9^{\text {th }}$ class B, 8.15-9 $9^{\text {th }}$ class $\left.C\right)$.

C.A.1.: Overall average obtained from current (formative) assessment sample 1 (8.25-A, 8.48-B, 8.32-C).

C.A.2.: Overall average obtained from current (formative) assessment sample 2 (8.40-A, 8.61-B, 8.50-C). 
Figure 5. Histogram of the results of the initial assessment; of current (formative) assessments 1, 2, and 3 in the lessons modeled after the empirio-psycho-sociocentric (EPS) combined model; and of the final, overall average (The $x$-axis: the assessment score out of 10)

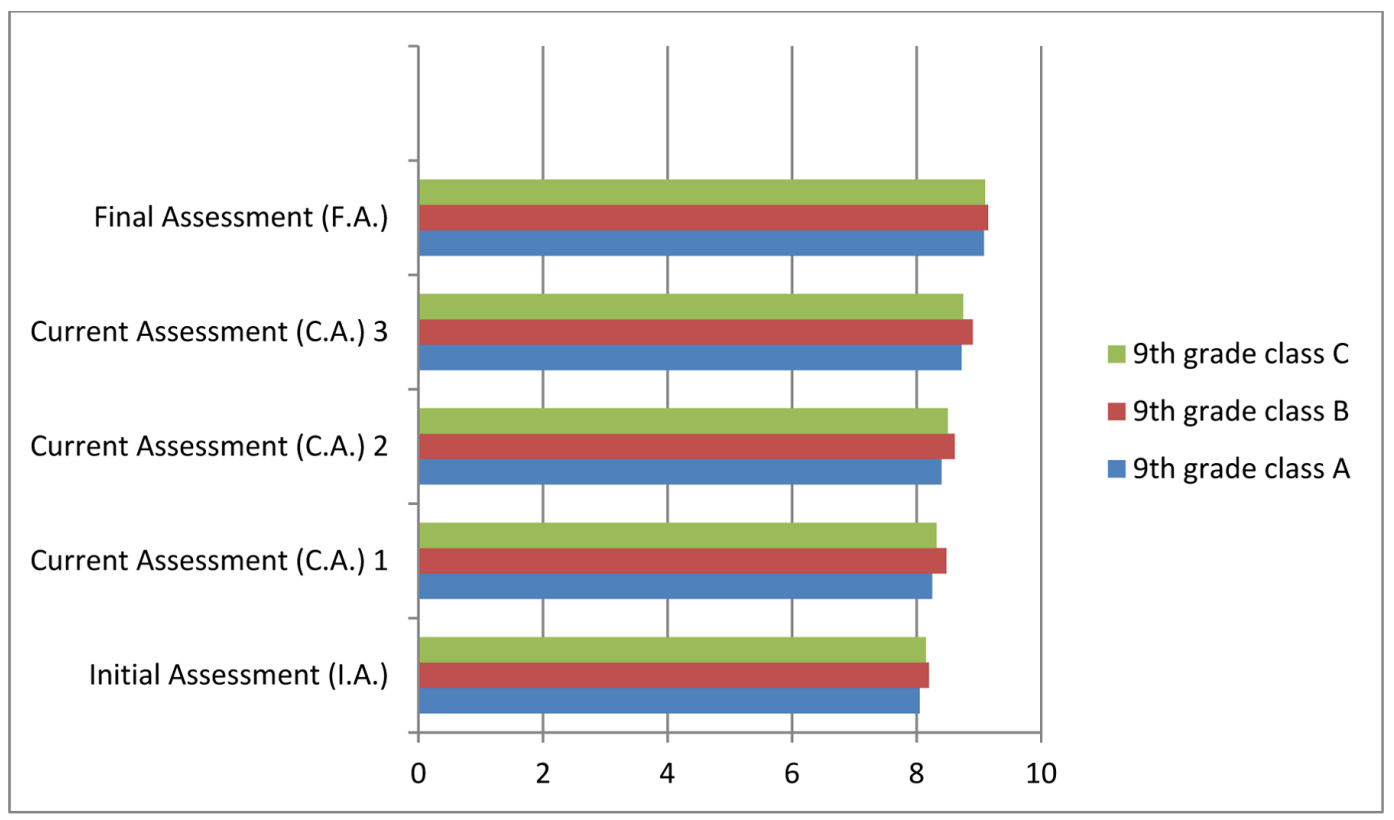

C.A.3.: Overall average obtained from current (formative) assessment sample 3 (8.72-A, 8.90-B, 8.75-C).

F.A.: Overall average of the final assessment sample $\left(9.08-9^{\text {th }}\right.$ class $A, 9.15-9^{\text {th }}$ class B, 9.10-9 $9^{\text {th }}$ class C).

- To improve the knowledge of Cytology, Histology, Anatomy and Physiology of plants and animals, correct understanding of human physiology and improve of their knowledge, amount thereof;

- Improvement of knowledge was demonstrated by a progressive increase in the general average in scores on assessments administered to classes of students; noting also the results of correlation indices, of median indices, and a decrease of the coefficient of variation;

- Such all the values of the correlation coefficients (r) of the results obtained at the experimental classes analyzed by analogy were increasing from the initial assessment to the final assessment and ranged from 0.75-0.95, which shows a better correlation of the results obtained by the students following the assessment of the cognitive acquisitions from the lessons in which the empirio-psycho-sociocentric (EPS) combined model was applied. Also, the values of the correlation coefficients showed the stronger connection between judgments in the processes of biological thinking;

- The median value $\left(\mathrm{E}^{\mathrm{MU}}\right)$, representing a position value that divides the series of students' grades into two, has increased from 8 to 9 , demonstrating the 
efficiency of applying of the empirio-psycho-sociocentric (EPS) combined model;

- The coefficient of variation (v) was between 0.158 and 0.100 , and decreasing, indicating that the statistical series are homogeneous and the overall average is representative and there are no errors in the selection of students groups for research;

- Teaching instruction was supported by the application of fundamental biological principles-i.e., "structure-function," "organism-environment," and "unity-diversity" correlations; and so on.

The positive effects of this model (which is based on rediscovering strategies) were especially beneficial for students, formatively. From the recorded data, the following benefits were:

- Developing strong operations of analysis, analogy, association, synthesis, abstraction and generalization, intuitive biological thinking, disciplinary and interand transdisciplinary, integrative, creative, original, visual memory and logic;

- Being shown how to solve problems in the classroom and at home-experiment, graphic, and object modeling; the essay quality; the summaries and reports, including the preparation of student-created, filled-out tables based on analogylevel reasoning; in correlation with the mental construction of biological concepts.

The application of the empirio-psycho-sociocentric (EPS) combined learning model based on constructionism by means of rediscovery strategies) elements in the study of human physiology, cellular physiology, and biochemistry. A greater capacity for analysis, analogy, synthesis, abstraction, generalization, training of the imagination, intuitive thinking, and visual memory. As shown by Petruta (2009), in the empiriopsycho-sociocentric (EPS) model, the following aspects are considered:

- The use of heuristic methods in lessons;

- The focus of the activity on the student;

- The giving of priority to individualized training independent work; but also on

- The centering of small groups'teams'activity around to them to better confront those initiatives;

- The cooperation and the development of interpersonal, socio-affective relationships (p.106).

The application of the empirio-psycho-sociocentric (EPS) combined learning model based on rediscovery strategies contributes to the formation/development of other intellectual skills. Such skills include:

- The modeling of biological knowledge;

- The capacity for individual and team documentaries; 
- The development of hypotheses;

- The solving of problems;

- The ability to verbalize the findings of experiments investigations;

- The building and developing of the spirit of research and experimentation (thus contributing to acquisition by students of qualities and behaviors similar to those involved in authentic scientific research); and so on.

In the meaning of today, science is no longer reduced to just the [given] amount of existing scientific knowledge. It is presented not only as a finished product, but also as a process [-] or, [perhaps] first and foremost, as a process. (Cerghit, 2006, p. 81)

Other benefits of the application of the empirio-psycho-sociocentric (EPS) combined didactical model based on rediscovery strategies refers to the formation and development of psychomotor skills specific to the study of biology, technical skills, and abilities with relation to specific work.

Rediscovery is greatly facilitated under circumstances which bring students to face challenges centered on cognitive and social conflicts. Cognitive challenges, are especially useful for discovering the laws and biological processes, with students being more active and stimulated in the process of the cognitive construction of new scientific knowledge through engaging in personal effort. Socio-cognitive conflict (the conflict that appears in social group at mental level between older concepts and new concepts for students) is an essential moment in stimulating group activity, including constructionism. The researcher highlights the benefits of autonomous work in a team and the superiority of cooperative situations in comparison with competitive ones. "The advantages of the former are that they create a social space that requires actors to meet new cognitive standards, to place themselves in a network of interdependencies generating conflicts and frequent centering, where repeated and successive integration of new knowledge operates better" (Cerghit, 2008, p. 181).

The constructionism of biological concepts trough rediscovering strategies would be more productive than other wise in terms of addressing specific problems by updating knowledge, by intra- and interdisciplinary correlative, experimental, and schematic representation, and heuristic conversation (e.g. determining the development of the relationship between photosynthesis and respiration), brainstorming (for example, in considering the significance of hygiene for health), and so on. Some elements of combinatorial applications, such as elements of the empiriocentric (E) model, based on rediscovery strategies, individual training, and student teams. Correspond to some of the elements of the psychocentric (P) and sociocentric $(\mathrm{S})$ models (empirio-psycho-sociocentric (EPS) combined didactical model). Developing team work skills; formation of an autonomous and creative personality; and applying the principles of complementarity and compensation. The issues mentioned above have been drawn from data analysis and interpretation collected through direct observation of students' behavior during lessons, in conducting activities within teams, but and in 
their using individual work sheets. "The collaboration tools enable students to engage in this scientific practice in a social context that includes other students, teachers, and scientists. The resulting social interactions enhance the learning that students achieve through the transformative process of communication" (Wilson, 1996, p. 162).

Rediscovery is more productive learning for students when using independent observations (e.g. observation of a fish's respiration). This is done by full conviction of the reality of the living world-i.e. the topography, morphology, composition, and physiology of biological systems located indifferent levels of organization of living matter-cellular components, cells, tissues, and so on. To support students and their rediscovery quickly and easily during lessons, mediated by natural teaching materials such as identifying even chest breathing by observation of the modification of volume and rotulian reflex, in these cases, were correlated to self-observation with laboratory experimentation.

It is very important and effective to apply the empirio-psycho-sociocentric (EPS) model in learning by the constructionism of specific concepts by doing individual activities and working in a team, and by linking laboratory experiments with independent observations. Because of forming and developing in students the investigative spirit; the skills relative to studying biological sciences with specific techniques; gaining a better understanding of the equipment, tools, and utensils in a laboratory; and developing the skills and abilities to use them. Because the interactions between students are very good and stimulate interactions between students and professors. Getting them to start conversations and to capacity for finding solutions to problems arising through oral communication are skills which are very necessary for working post-school.

An example of the application of the empirio-psycho-sociocentric (EPS) combined learning model is an identification of old, altered, and toxic meat (Figure 6) in biochemistry, as a branch of biology, by second-year students of the Control and Expertise of Food Products Faculty and of Food Products Engineering Faculty at the Bioterra University in Bucharest. The investigation by laboratory experiments was to identify old food, which is toxic to the body, based on determining the presence of ammonia in free form using the Nessler method in meat samples. The principle consists of identifying the ammonia in a free state of aqueous extract of the sample to be analyzed forms with tetraiod-mercuriat-dipotassium, $\mathrm{K}_{2}\left[\mathrm{HgI}_{4}\right]$, (Nessler reagent) a yellow-orange complex (oxidation of mercury ammonium). As such, the results of the laboratory experiment for identification the old, altered, and toxic meat were as follows: In a tube with fresh meat extract, the solution did not change color or even clarity even after adding 10 drops of Nessler reagent; the reaction was very negative in that ammonia in its free state was not detected, because the meat was fresh (Figure 6, flask $\mathrm{C}$ ). The tube with a relatively fresh meat extract solution became pronouncedly yellow in color, and a slight precipitate appeared after adding 6 drops of Nessler reagent: the reaction was positive but very weakly so, ammonia being present only in small amounts, because the meat was relatively fresh (Figure 6, flask B). In the tube with an extract of old meat (which had), the solution became yellow and orange in 
color; and an abundant precipitate of the same color appeared, even after only adding the first 2-3 drops of Nessler reagent: thus, the reaction was positive; ammonia was present in large amounts, because the meat was old, and had (Figure 6, flask A). Various qualities of fresh, relatively fresh, and old pork meat (muscle).

Flasks a, b, and c.

The laboratory experiments were completed with discussions and debates. The students responded to some questions previously mentioned and addressed by professor to their on the ethics of the commercialization of food that is old, of donations of old food to charities as tax write-offs to reduce business taxes and at risk of having turned/spoiled.

This combined learning model is based on rediscovery by means of:

- Laboratory experimentation and observation-elements of the empiriocentric (E) model which correspond to Papert's constructionism (learning by doing);

- Discussions and debates, as elements of the sociocentric (S) model; and

- Individual student work sheets, as an element of the psychocentric (P) model.

\section{THE TECHNO-EMPIRIO-PSYCHO-SOCIOCENTRIC (TEPS) COMBINED LEARNING MODEL}

In biology lessons or courses, elements of the technocentric $(\mathrm{T})$ model are used by using ICTs in combination with elements of the empiriocentric (E) model, rediscovering new

Figure 6. Identification of old and toxic meat, by meat extract solutions used: (a) Tube with old, extract meat; (b) Tube with relatively fresh meat extract solution; (c) Tube with fresh meat extract solution

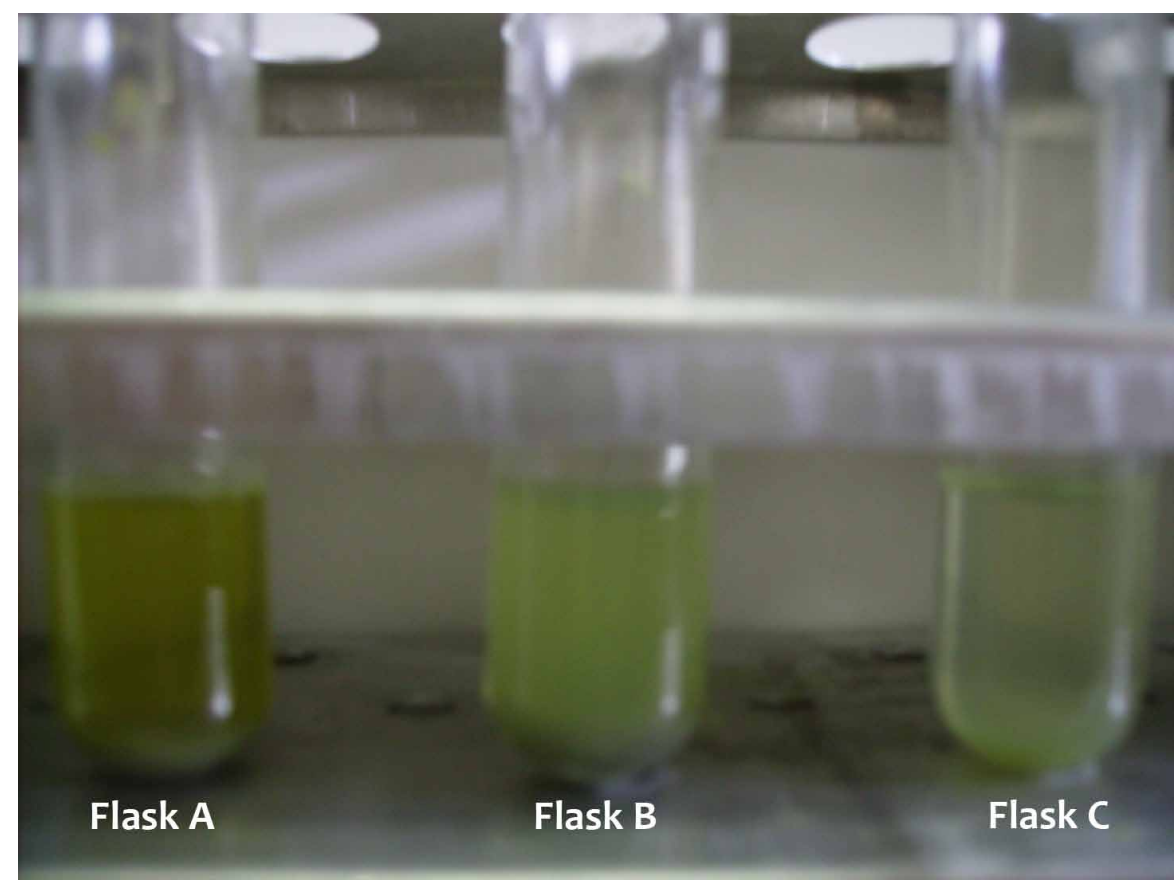


biological concepts. For example, by exploratory observation, electronic simulation, electronic experimentation with the computer, depending on the individual and age particularities of the students, which correspond to the psychocentric (P) model. Sociocentric activities are also organized. Then, the model is a combined one, and is called a techno-empirio-psycho-sociocentric (TEPS) model.

An example of applying this techno-empirio-psycho-sociocentric (TEPS) combined model based on Papert's constructionism-e.g., technology as a building material (being especially true for digital technology); learning by doing; and learning to learn - is the sequence of endocrine gland anatomy, in an $11^{\text {th }}$ biology class on human anatomy and physiology. This is rediscovered-both individually and in a team-with the aid of ICTs. The endocrine glands in women. The pituitary, the epiphysis, the thyroid, the thymus, the endocrine pancreas, the adrenals, and the two ovaries and the placenta in pregnancy can be studied by using animated sequences their location to be discovered when students pass the mouse over a of a woman's body. Clicking on the image with the gland, located at the level of the body, will open a window in which, like a graph with an ordered and an abscissa, each gland, where the abscissa represents the horizontal (X) axis, and the ordered axis is the vertical (Y) axis. Moves with the mouse from the 0 -origin point on the abscissa axis, the anterior and posterior face of the endocrine glands are observed. By moving the mouse from the 0-origin point on the ordered axis, the cranial pole and caudal pole of the endocrine glands are observed. Beyond the animation-based rediscovery of the external location and morphology of the endocrine glands, the sequence allows for e-learning about each endocrine gland, in part by using the mouse to click on its name, which opens another window with details about the location, shape, size, weight, structure, and secreted hormones. After to learn about the female endocrine glands, a similar process can enable students to learn about male glands as well: the pituitary, the epiphysis, the thyroid, the thymus, the endocrine pancreas, the two adrenals, and the two testicles. This example of learning includes the application of ICTs, exploratory observation, demonstration, simulation, and electronic reading, etc., within the techno-empirio-psycho-sociocentric (TEPS) didactic model. In it, students-by their own efforts - rediscover biological

Table 1. Learning modalities in a "euthanasia and bioethics" lesson the techno-empirio-psycho-sociocentric (TEPS) model

\begin{tabular}{|c|l|l|}
\hline $\begin{array}{c}\text { Cur. } \\
\text { No. }\end{array}$ & $\begin{array}{c}\text { Content } \\
\text { (Lesson) }\end{array}$ & $\begin{array}{l}\text { Learning Modalities in the Techno-Empirio-Psycho-Sociocentric (TEPS) Combined } \\
\text { Model }\end{array}$ \\
\hline 1. & $\begin{array}{l}\text { Euthanasia } \\
\text { and } \\
\text { bioethics }\end{array}$ & $\begin{array}{l}\text { Watching movies euthanasia (Arbelaez, 2007; Benedetti, 2007) as a frontal-activity a } \\
\text { computer, a video projector, an electronic board, the Internet, and YouTube. } \\
\text { Rediscovery of the concept of euthanasia by chat discussion about the euthanasia } \\
\text { presented in the movies watched (a group activity). } \\
\text { Documenting (using a computer and the Internet) euthanasia practices in the world; and } \\
\text { realization of interdisciplinary correlations with geography (countries, continents, etc.) } \\
\text { by means of the activity the students' team. } \\
\text { Documenting (using a computer and the Internet) the penal code, which does not allow } \\
\text { for euthanasia (an individual activity). } \\
\text { Debate and argumentation in chat for or against euthanasia (a group activity). }\end{array}$ \\
\hline
\end{tabular}


knowledge by means of techniques and hardware-computer resources such as a monitor, mouse, and educational software (entitled "Interactive Biology Lessons"). The team activity is realized by comparative analysis and discussion, by students, about female and male glands. These activities correspond to Papert's constructionism ideas, that refer to knowing about digital technology being as important as reading and writing; technology as being building material (which is especially true of digital technology); learning by doing; and learning to learn. Such contribute to the formation development of intellectual skills.

Another example of the application of the techno-empirio-psycho-sociocentric (TEPS) model is its application in a $12^{\text {th }}$ grade (high school) "euthanasia and bioethics" class lesson, with regard to biological content within the scientific disciplines. Instruction occurs through e-learning — such as through watching movies with the aid of the Internet, a computer, a video projector, an electronic board, YouTube, chat discussions, and so on, as follows (Table 1).

In the knowledge society, the process of communication is also changing. As shown by Castells (2007), this change is due to the fact that communication is based on digitized, cross-linked interaction and binary communication and that it focuses on the Internet and networks.

The techno-empirio-psycho-sociocentric (TEPS) combined learning model, in the constructionism of concept, cultivates school/university pupils'/students' internal motivation to learn.

\section{THE LOGO-PSYCHOCENTRIC MODERNIZED (LPM) COMBINED LEARNING MODEL AND THE CONSTRUCTIONISM OF BIOLOGICAL CONCEPTS-BENEFITS AND NEEDS}

The researcher thinks that the techno-empirio-psycho-sociocentric (TEPS) combined learning model and the empirio-psycho-sociocentric (EPS) combined learning model, applied to the learning of new biological knowledge in the form of individual and team organization, should not be absolutized. Some caution in their use in learning concepts of cytology, histology, human physiology, and so on required. Not all biological knowledge can be studied and assimilated best by the path of rediscovery. In alternation or in combination with these models, the logo-psychocentric modernized (LPM) model could be used functionally and as needed, for contributing to higher cognitive improvements. Are obtain by the use of practices inspired from learning by means of the logocentric (L) model, adapted to the individual particularities of students-provided that the best attractive procedures (per the logo-psychocentric modernized, or LPM, model) are used. Among the most attractive procedures with effective roles in lessons, the following have been used successfully:

1. Working with scheduled instruction and evaluation sheets;

2. Useful inter- and transdisciplinary correlations, made indifferent ways:

a. References to scientific texts; 

b. References to literary texts;
c. Recitation of verses;
d. Submission of artwork;

3. Simulations;

4. Practical activities, sometimes with a heuristic nature; and so on.

This logo-psychocentric modernized (LPM) model is for implementation in:

- With many biological concepts that surprise students with their novelty;

- Greater diversity;

- Which lacks "anchor" concepts on which to support new school learning;

- Some concepts which may be difficult (or even impossible) to easily rediscover (or where rediscovery could likely be achieved only on the basis of graphical models);

- There is missing the natural biological material for observing or experimenting with it.

For example, with the application of the logo-psychocentric modernized (LPM) model, results were obtained for $9^{\text {th }}$ grade class lessons on "the mitotic cycle" and "the meiotic cycle" and for class lessons on "embryonic plants tissues" and "definitive plants tissues" (Figure 5), at "Ion Luca Caragiale" National Collegium in Bucharest in 2015. These results were better in comparison with the results obtained by the application of logocentric (L) (traditional) or of empirio-psycho-sociocentric (EPS) models. Lessons were conducted by the application of the logo-psychocentric (LP) model, which was by combining it with attractive procedures. Based on the pedagogical observation, the following conclusion was reached: students' behavior during their activity intensifies, as does thinking, epistemological curiosity and interest. Each student learns to organize their; to on their own; and to put effort into finishing a task. Their work within a scheduled; and document. Contributes to the formation of an autonomous personality. The student is isolated from the group, with negative effects on the formation of certain personality traits. It creates conditions for social interaction and cognoscibility. It concludes with the need for combining individual work with work as a team; and to organize activities teams of students.

There is a need for a period of adaptation with this learning approach, by the application of the logo-psychocentric modernized (LPM) model. This was demonstrated by the results obtained from all $9^{\text {th }}$ and $10^{\text {th }}$ grade classes (Figure 7 ) in which the experimental research has been applied. Within lessons in which the logo-psychocentric (LP) model, with attractive procedures (LPM), had been implemented, was current (formative) assessment showed a progressive increase in the overall average of:

The x-axis: the assessment score out of 10 . 
Figure 7. Histogram of the results of the initial assessment; of current assessments 1 and 2 in the lessons modeled after the logo-psychocentric modernized (LPM) model; and of the final, overall average

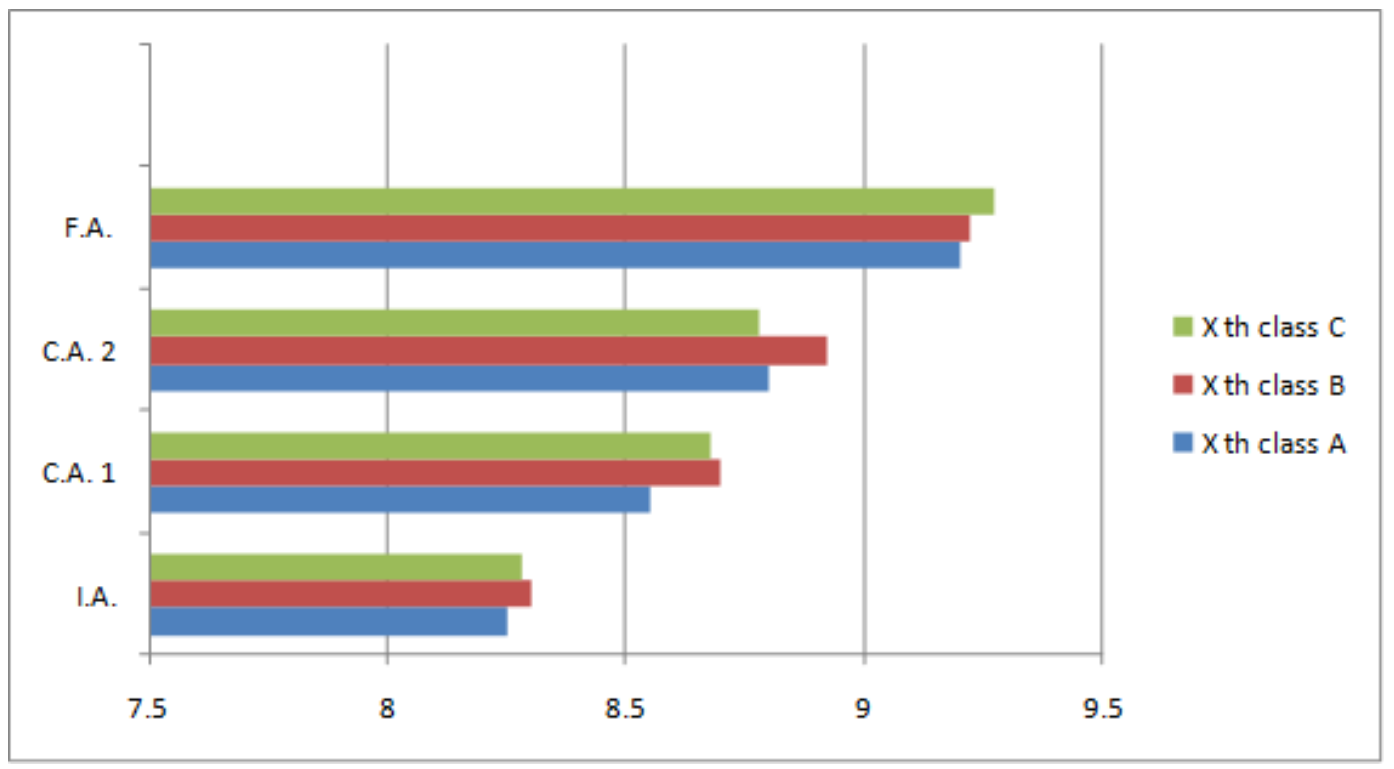

I.A.: Overall average of the initial assessment (8.25-class A, 8.30-class B, 8.28-class C).

C.A.1.: Overall average obtained from current (formative) assessment sample 1 (8.55-A, 8.70-B, 8.68-C).

C.A.2.: Overall average obtained from current (formative) assessment sample 2 (8.80-A, 8.92-B, 8.78-C).

F.A.: Overall average of the final assessment (9.20-class A, 9.22-class B, 9.27-class C).

The researcher thinks that combining different learning models contributes to the bettering and modernization of the education of students: intellectual, health, and ecological education, moral, civic, altruism education, respect for the opinions of others, tolerance, democratic behavior and honesty, education for science, aesthetic, and work, and so on. High efficiency in affective education can be achieved through the combination of multiple learning models (techno-, empirio-, psycho-, sociocentric).

\section{THE TECHNO-LOGO-PSYCHOCENTRIC (TLP) LEARNING MODEL AND THE CONSTRUCTIONISM OF BIOLOGICAL CONCEPTS-BENEFITS AND NEEDS}

Researchers encourage teachers to improve their skills of integrating digital technologies in education that would help students develop their information analysis and evaluation skills in the learning process, which in turn, would decrease the scope of the possible risks caused by digitalization. (Rubene, 2018, p. 16) 
The techno-logo-psychocentric (TLP) combined model is modernized by means of the use of multimedia digital technologies, as elements of the technocentric (T) model. These include the use of the laptop, the computer program, the video movie, and the smartphone, of the computer-programmed training sheets, working sheets, inter- and trans-correlations of biology with other disciplines, and science being presented as a finished product; correspond to the logocentric (L) model, according to individual and age-related particularities; doing so corresponds to the psychocentric $(\mathrm{P})$ model. Other attractive procedures in the techno-logo-psychocentric (TLP) model are: Computer Assisted Instruction (C.A.I.) and the use of the Internet, digital video discs (DVDs), and compact discs (CDs). Heretofore, the advantages of computer usage in learning "saving time, cognitive achievement, facilities for simulation of phenomena, processes, shares by [means of learning occurring in a shared digital environment] computer skills" (Cerghit, Neacşu, Negreţ-Dobridor, \& Pânişoară, 2001, p. 99), projector transparencies, and PowerPoint slides. The launching of Microsoft's PowerPoint in the late 1980s "is considered by many educators [as being] a milestone in the history of Technology Enhanced Learning” (Stefanou \& Kotsovoulou, 2016, p. 38).

The techno-logo-psychocentric (TLP) model can be used, for example, in learning about various "molds" in a course on that topic within the discipline of general microbiology. Students can be captivated by interesting and engaging teaching in which a professor's supporting lecture presents the science as finished product already discovered by scientists. Combining logocentric (L) activity- based on science and teacher with technocentric (T) activity-according to students' individual abilities (a method which corresponds to the psychocentric (P) model) - in which students watch short, English-language videos about molds useful and harmful to humans. This corresponds to the technocentric (T) learning model. Pedagogical observations were made of general microbiology faculty's teaching of first-year students in the Control and Expertise of Food Products program at Bioterra University in Bucharest. The techno-logo-psychocentric (TLP) combined model was applied. It turned that some conditions are needed in order to be fulfilled. It is absolutely necessary for an understanding of (English) and work skills with technical means, as the laptop and the Internet. Other elements of modernization - attractive procedures used in applying techno-logo-psychocentric (TLP) combined model to general microbiology coursesinclude computerized working sheets for students; studying Latin root words so as to better understand biological terminology, e.g. the etymological basis for standard vocabulary terms in general microbiology; and correlations with the English language for understanding of the scientific content of videos. Pedagogical observations have shown that students who have been trained in the (applied) techno-logo-psychocentric (TLP) combined model:

- Enhanced interest

- A stimulated curiosity

- Epistemological interest 
They also:

- Interactivity;

- Gains a better ability to ask the teacher questions;

- Work with new information and communication technologies;

- Understand active listening the scientific message of English-language videos, which contributes to the formation of necessary research capacities in their future profession.

\section{CONCLUSION AND RECOMMENDATIONS}

The researcher showed that in the learning of cytology, general microbiology, biochemistry, histology, and the anatomy and physiology of vegetable and animal organs, human anatomy and physiology obtains the best results in terms of the construction of biological concepts by students' efforts.

The combination of didactic models based on Papert's constructionism ideas-e.g. those that refer to learning by doing; and to building materials (which is especially true of digital technology and knowing about digital technology) offer cognitive, formative, and emotional benefits; and the students' role being maximized the teacher's role minimalized - is both important and necessary.

The researcher recommends that in biological lessons and courses, a technoempirio-psycho-sociocentric (TEPS), or techno-heuristic-psycho-sociocentric (THPS), combined learning model be used for the construction of new biological concepts by the efforts of pupils/students using the new ICTs:

- Would be in accordance with intellectual;

- Technique and skills;

- It would facilitate the formation and construction of cognitive schemas;

- Their talents and interests;

- It would take the for professional social.

The benefits of learning with the empirio-psycho-sociocentric (EPS) combined model use ICTs are also. Learning by rediscovery and constructionism (in all their forms) is necessary in modern biological education. Because are centered on the productive activities of students, and have formative advantages. However, there are some disadvantages, obstacles that must be overcome, e.g. lack of "anchor" concepts, to support for learning of new biological concepts, the difficulty of rediscovering some notions, some even impossible to rediscover due to inadequate material basis. Also, are certain didactical conditions that must be assured e.g. didactical materials for experiment in order learning by rediscovery, biology laboratory organized etc.

In alternation or in combination with the techno-empirio-psycho-sociocentric (TEPS) learning combined model, or the empirio-psycho-sociocentric (EPS) learning combined model, a techno-logo-psychocentric (TLP) combined learning model can 
be applied, where the science is presented as a finished product, with respect to the individual particularities of students, and using technologies, as attractive and productive procedures, e.g. digital technologies (multimedia presentations). Also, can be applied the logo-psychocentric modernized (LPM) model, where the science is presented as a finished product, but with others attractive and productive procedures. For instance, such procedures might include:

- Simulations of biological phenomena and processes;

- Scheduled instructional sheets for application of scheduled training (the subject matter is presented as a program based on a set of principles);

- Interdisciplinary correlations, the correlations between biological concepts and the concepts studied at the other educational objects in the same curricular area with Biology - "mathematics and natural sciences," e.g. the correlation with mathematics in calculating the ratio of gene segregation following hybridization, in the study of Mendelian laws; and

- Transdisciplinary correlations, the correlations of biological concepts with the concepts studied in disciplines from areas other than curricular areas than that in which Biology is included (e.g. in learning of morphological peculiarities of the plant organs can be recited verses about plants, written by the greatest poets, can be demonstrated paintings of famous painters).

These procedures depending on the content and instructional objectives, the nature of capacity of students and the availability material resources. 


\section{REFERENCES}

Ackermann, E., Gauntlett, D., \& Weckstrom, C. (2009). Defining systematic creativity: Explaining the nature of creativity and how the LEGO system of play relates to it. Billund, Denmark: LEGOR Learning Institute.

Alessandrini, K., \& Larson, L. (2002). Teachers bridge to constructivism. The Clearing House: A Journal of Educational Strategies, Issues and Ideas, 75(3), 118-121. doi:10.1080/00098650209599249

Arbelaez, C. (2007, November 9). Euthanasia [Video file]. Retrieved from http://www. youtube.com/watch?v=GOH5jTwMo4A

Benedetti, M. (2007, September 8). Euthanasia [Video file]. Retrieved from http:// www.youtube.com/watch? $v=$ _ucbSPiN2j4

Castells, M. (2007). The information society. Warsaw, Poland: Polish Scientific Publishers PWN.

Cerghit, I. (2006). Educational methods. Iaşi, Romania: Polirom.

Cerghit, I. (2008). Alternative and complementary training systems. Structures, styles and strategies. Iaşi, Romania: Polirom.

Cerghit, I., Neacşu, I., Negreţ-Dobridor, I., \& Pânişoară, I.-O. (2001). Pedagogical lectures. Iaşi, Romania: Polirom.

Ciobanu, M. (2003). Alternative models of instruction used in biological education. Unpublished doctoral dissertation, University of Bucharest, Bucharest, Romania.

Daniela, L., Kalnina, D., \& Strods, R. (2017). An overview on effectiveness of Technology Enhanced Learning (TEL). International Journal of Knowledge Society Research, 8(1), 79-91.https.doi.org/10.4018/IJKSR.2017010105

Daniela, L., \& Lytras, M. (2018). SMART pedagogy: (Re)Defining pedagogy. In L. Daniela \& M. Lytras (Eds.), Learning Strategies and Constructionism in Modern Education Settings (pp. 1-15). Hershey, PA: IGI Global. doi:10.4018/978-1-52255430-1.ch001

Iancu, M. (2018a). Electronic-learning and the virtual reality in biology. International Journal of Current Research, 10(5), 69198-69205. doi:10.24941/ijcr.2017

Iancu, M. (2018b). Learning models and strategies and the constructionism in modern education settings: With applications in modern learning of biology. In L. Daniela \& M. Lytras (Eds.), Learning Strategies and Constructionism in Modern Education Settings (pp. 197-222). Hershey, PA: IGI Global. doi:10.4018/978-1-5225-5430-1. ch012

Organisation for Economic Co-operation and Development. (2015). E-learning in Higher Education in Latin America. Paris, France: OECD Publishing. 
Papert, S., \& Harel, I. (1991). Situating constructionism. In S. Papert \& I. Harel (Eds.), Constructionism. Retrieved from www.papert.org/articles/SituatingConstructionism. html

Papert,S. A. (1987, May 11). Constructionism: A New opportunity for elementary science education [Abstract]. National Science Foundation, Division of Research on Learning in Formal and Informal Settings. Retrieved from http://nsf.gov/awardsearch/ showAward?AWD_ID=8751190

Papert, S. A. (1993). The children's machine: Bringing the computer revolution to our schools. New York, NY: Basic Books.

PapertS. A. (1999, March 29). PapertonPiaget. Time. Retrieved from http://www. papert.org/articles/Papertonpiaget.html

Petruța, G.-P. (2009). Didactical lectures of biological sciences. Pitești, Romania: University of Piteşti Publishing House.

Rubene, Z. (2018). Integration approaches of digital media in the teaching/learning process. In L. Daniela \& M. Lytras (Eds.), Learning strategies and constructionism in modern education settings (pp. 16-24). Hershey, PA: IGI Global. doi:10.4018/9781-5225-5430-1.ch002

Stager, G. (2005). Papertian constructionism and the design of productive context for learning. In Proceedings of the Tenth European Logo Conference. Warsaw, Poland: Centre for Informatics and Technology in Education.

Stefanou, V., \& Kotsovoulou, M. (2016). Use of PowerPoint in the classroom: A participatory research project. International Journal of Knowledge Society Research, 4(7), 38-50. https.doi.org/10.4018/IJKSR.2016100104. doi:10.4018/ IJKSR.2016100104

Wilson, B. (1996). Constructivist learning environments: Case studies in instrumental design. Englewood Cliffs, NJ: Educational Technology Publications. 